\title{
A viagem como formação
}

Travel as training

Viajar como entrenamiento

Marco Garaude Giannotti ${ }^{1}$

1 Marco Garaude Giannotti: Pintor e professor associado do Departamento de Artes Plásticas da USP.

Currículo Lattes: http://lattes.cnpq.br/9886309524100476 


\section{Resumo}

O texto discorre sobre como o ato de viajar pode despertar e formar um pensamento plástico. Neste sentido, uma série de considerações históricas confere diferentes sentidos a uma atividade que embora extra cotidiana, acaba por propiciar uma dimensão estética ao simples ato de ver o mundo ao redor numa nova perspectiva.

\section{Palavras-chave}

viagem, fenomenologia, paisagem urbana.

\section{Abstract}

The text discusses how the act of traveling can awaken and form a plastic thought. In this sense, a series of historical considerations gives different meanings to an activity that, although extra daily, ends up providing an aesthetic dimension to the simple act of seeing the world around in a new perspective.

\section{Keywords}

travel, phenomenology, urban landscape.

\section{Resumen}

El texto discute cómo el acto de viajar puede despertar y formar un pensamiento plástico. En este sentido, una serie de consideraciones históricas le da diferentes significados a una actividad que, aunque es más diaria, termina proporcionando una dimensión estética al simple acto de ver el mundo en una nueva perspectiva.

\section{Palabras clave}

viajes, fenomenología, paisaje urbano.

ISSN: 2447-1267 
EXISTEM TANTOS ESTILOS DE

VIAJAR QUANTAS FOREM AS

ÉPOCAS DA VIDA HUMANA.

Arley Andriolo

Em o Olhar Viajante o antropólogo Sergio Cardoso, baseado em MerleauPonty, desenvolve dois aspectos importantes para nossa análise. O primeiro é a distinção entre ver e olhar, presente entre várias outras línguas como ver e mirar, voir e regarder, see e look, vedere e sguardo etc. $O$ "ver denota no vidente uma certa discrição e passividade ou ao menos alguma reserva... Com olhar é diferente, ele remete de imediato, à atividade e virtudes do sujeito..." (CARDOSO, 1988, p. 347). Mesmo na nossa cidade, podemos passear pela avenida Paulista a esmo, de maneira desinteressada, esperando passivamente os acontecimentos se desvelarem diante de nós. Podemos trafegar as pressas, sem olhar para nada, buscando chegar o quanto antes à avenida da Consolação ou ao bairro do Paraíso.

Por outro lado, se tivermos uma predisposição para realizar uma análise artística ou científica, passamos olhar e indagar os fenômenos com maior interesse, buscando uma análise ora formal, causal ou de outra natureza.

Mas é quando viajamos, principalmente para lugares desconhecidos, que a nossa percepção parece mais aguçada. Em 2011 tive a oportunidade de morar no Japão, um país até então inteiramente desconhecido para mim. Pelo fato de não conhecer a língua, me sentia um analfabeto ambulante, olhando para as palavras numa perspectiva estética. Este estado de dépaysement do viajante é o segundo aspecto abordado por Cardoso em seu artigo. Uma sensação constante de alheamento e de estranhamento da realidade que permite olhar para outros mundos e formas de vida.

Porém, isto não significa que qualquer viagem efetivamente possa produzir esta sensação. A indústria turística produz mundo a fora a viagem como mais uma mercadoria a ser consumida e digerida em quinze minutos. Aparatos digitais produzem a falsa sensação de que tudo está sendo registrado integralmente a cada instante. Não há nenhuma sensação de estranhamento, mas antes uma atitude de consumo permanente. Os percursos são sempre os mesmos e acabam inevitavelmente em uma loja para adquirir uma lembrança. Impossível assim se perder a fim de se deparar efetivamente com o desconhecido.

Desde a antiguidade, contudo, "as viagens de Telêmaco ao Egeu demonstram que já na época de Homero a cultura era considerada, acima de tudo, conhecimento de cidades" (ARGAN, 1992, p. 244). Logo no início Homero celebra aquele que "de muitos homens viu urbes e a mente conheceu" (HOMERO, 2014, s/p). A Odisseia até hoje aparece como uma atividade emblemática da humanidade, ao ponto de mesmo viagens imaginadas no futuro se configuram como uma Odisseia no espaço, como no filme de Stanley Kubrick'. Livros lapidares para nossa formação ocidental como

\footnotetext{
${ }^{1}$ No movimento histórico de elevação da visão, Goethe introduz um olho em formação com os fenômenos e em
} 
a Bíblia estão permeadas por viagens e migrações épicas como a travessia do mar vermelho ou na fuga para o Egito.

Em torno de 1300, aparece o livro das maravilhas do mundo, também conhecido como as viagens de Marco Polo que retratam com grande vivacidade a viagem deste mercador por toda a rota da ceda até chegar a China. Célebres navegantes como Cristóvão Colombo irão se pautar em Marco Polo como um exemplo a ser seguido.

Relacionando com tema da nossa pesquisa sobre as cidades vale lembrar como Ítalo Calvino com grande destreza em seu livro cidades invisíveis associa o tema da viagem com a capacidade de criar cidades imaginárias quando Marco Polo narra as cidades que conheceu para o grande chefe mongol Kublai Kahn.

Petrarca viajou intensamente pela Europa e trabalhou como embaixador. Durante suas viagens, colecionou manuscritos latinos antigos e assim tornou-se um dos primeiros a redescobrir a cultura clássica. Realizou a primeira tradução latina de Homero em 1345. Petrarca foi o primeiro homem a escalar uma montanha pelo prazer da subida ou para ver o mundo de cima e contemplar o horizonte. Foi deste modo um observador consciente de sê-lo². Neste sentido, contemplar a natureza é uma atitude moderna ${ }^{3}$. "Sou eu mesmo a matéria do meu livro" afirmará mais tarde Montaigne, percussor do ensaio, modelo literário muito adequado para relatar viagens. Já Descartes em seu discurso sobre o método (1637) afirma que nada aprendeu na escola que fosse relevante para a vida. A fim de apreender com o mundo, pôs o pé na estrada e viajou intensamente pela Europa4 (FIGUEREDO, 2018).

Durante muito tempo viajar era uma atividade muito perigosa, pois ao sair de uma cidadela fortificada, as estradas não eram seguras e o sujeito se expunha aos mais diversos riscos, do ataque de animais selvagens a emboscadas de bandidos. Impossível não se aventurar no mar sem encontrar piratas. Em Dom Quixote, vemos as dificuldades do gentil fidalgo embrenhado nos livros de cavalaria permeados de aventuras se deparar com a dura realidade dos fatos.

A partir do Renascimento, com a retomada dos ideais clássicos, todo artista que buscava uma formação mais ampla deveria ir visitar Roma. Brunelleschi viaja de Florença para lá com Donatello e aprende as sutilezas do método construtivo

referência à estética. A Odisseia tornou-se uma "palavra viva", porque, a partir de então, lia Homero "como se me houvessem retirado a coberta de cima dos olhos" Apud ANDRIOLO, ARLEY. Metamorfoses do olhar - viagem de Goethe à Itália, p.125.

2 WILLIANS, R. O campo e a cidade. Cia das letras, São Paulo.

"Petrarca era um observador consciente de sê-lo: o homem que não apenas contempla a terra, mas também tem consciência do que está fazendo como uma experiência em si, e preparou modelos sociais e analogias tiradas de outros campos para apoiar e justificar a experiência."

3 Contemplar, contemplare em latim, surge da união de Com + Templum. O dicionário Oxford de latim-inglês nos diz que contemplar entre outras coisas é o lugar de observação do Augur, palavra latina que designa aquele que observa e interpreta o comportamento dos pássaros é, em suma, um vidente ou profeta. Temos em português a palavra augúrio, que significa presságio, prognóstico, auspício e que também vem do latim. Contemplar em inglês arcaico tem o sentido de habitar o mesmo templo. Schiller, nas Cartas sobre a Educação Estética do Homem, nos diz que contemplar é a primeira relação livre (das erste liberal verhältnis).

4 A fim de apreender com o mundo, pôs o pé na estrada e viajou intensamente pela Europa. Em 1618, alista-se nas tropas de Maurício de Nassau, quase vindo combater por nossas terras, por conta da ocupação holandesa no Nordeste brasileiro. 
antigo, cuja técnica de amarração de tijolos será de grande serventia para a realização da cúpula de Santa Maria dei Fiori. Michelangelo e Rafael estudam os mármores recentemente escavados e que inaugura o nascimento da arqueologia com Winckelman ${ }^{5}$. Há uma grande afluência para lá de artistas europeus graças ao mecenato do Vaticano com todos seus cardeais riquíssimos. Artistas de culturas tão diversas como Velázquez, Claude Lorrain, Poussin consideram uma estadia em Roma uma experiência fundamental na sua formação. A partir de 1666 a criação da academia francesa em Roma facilita a estadia de artistas franceses. Mas não se trata de pintar ao ar livre a paisagem romana, trata-se antes de buscar uma paisagem ideal: primeiro com temas bíblicos depois com a temática mitológica. Curiosamente é neste momento que a natureza passa a ser vista numa perspectiva não aristotélicab.

A partir do século XVII firma-se na pintura européia o estudo da paisagem principalmente devido a propagação da pintura italiana e sua relação dialética com a pintura dos países baixos. Entretanto, no interior da paisagem, muitas vezes vestígios da civilização sempre aparecem para balizar nosso olhar. Por exemplo, tanto na famosa Tempestade de Giorgione de 1508, uma das primeiras pinturas com o tema da paisagem, como na pintura de Poussin Paisagem com São João em Patmos realizada 1640 observa-se no primeiro plano ruínas antigas que remetem a figuras geométricas. No caso de Poussin, no meio plano aparece ainda ruína de um templo, um pouco mais ao fundo um obelisco e por fim uma montanha. O que torna fascinante esta pintura é justamente este jogo entre natureza e cultura que permite a contemplação da natureza. É graças a presença de formas geométricas que o olhar pode chegar até a montanha vista à distância e que, por sua vez, sugere a figura de um triangulo perfeito ${ }^{7}$. As pinturas de Poussin e Claude Lorrain se tornaram paradigmáticas para novas construções de jardins para os viajantes ingleses segundo Raimond Willians ${ }^{8}$.

\footnotetext{
${ }^{5}$ Winckelmann (1717-1768), com sua História da arte na Antiguidade, de 1764. Como aponta a historiografia, essa publicação representou a primeira aparição em um título de livro da frase "história da arte". A respeito desse autor, Goethe escreveu: "foi Winckelmann o primeiro que urgiu em nós a necessidade de distinguir várias épocas e traçar a história dos estilos em seu gradual crescimento e decadência". APUD ANDRIOLO, Arley. ANDRIOLO, ARLEY. Metamorfoses do olhar- viagem de Goethe à Itália. ArtCultura, Uberlândia, v. 13, n. 23, p. 113-127, juldez. 2011.

${ }^{6} \mathrm{Na}$ segunda metade do século XVIII pela primeira vez no ocidente, a ideia da natureza não é mais sistematicamente associada aos quatro elementos (ar, agua, terra, fogo) como era feita desde Aristóteles mas a vegetação: Doravante, é feita da prados e de madeira, de arvores e de florestas, de folhas e galhos. PASTOUREAU.M. Hitoire du noir.

7 Ver a este respeito GIANNOTTI. M. Veneza, em Volpi. Revista ars n.34 e BERESON, the Italian painters of the Renaissance- The first modern landscapes:

Another thing Bassano could not fail to do working as he did in the country, and for country people, was to paint landscape. He had to paint the real country, and his skill in the treatment of height and atmosphere was great enough to enable him to do it well. Bassano was in fact the first modern landscape painter. Titian and Tintoretto and Giorgione, and even Bellini and Cima before them, had painted beautiful landscapes, but they were seldom direct studies from nature. They were decorative backgrounds, or fine harmonizing accompaniments to the religious or human elements of the picture. They never failed to get grand and effectivenes-a setting worthy of the subject. Bassano did not need such setting for his country versions of Bible stories, and he needed them even less in his studies of rural life. For pictures of this kind the country itself naturally seemed the best background and the best accompaniment possible-indeed, the only kind desirable. Without knowing it, therefore, and without intending it, Bassano was the first Italian who tried to paint the country as it is, and not arranged to look like scenery.

${ }^{8}$ Os proprietários rurais setecentistas, ao viajarem pelo continente europeu e colecionarem quadros de Poussin e Claude, apreenderam novas maneiras de ver a paisagem e, ao voltarem para a Inglaterra, criaram novas paisagens para serem desfrutadas de suas próprias casas....Sobre as viagens pitorescas: conhecer os lugares famosos,
} 
Representar a grandeza desta cidade por meio de estampas torna-se um meio reprodutível extremamente eficaz, como no caso da vedutas de Piranese. A estampa se torna o cartão postal de então. Vale lembrar que uma viagem demorava no mínimo um ano devido ao sistema precário de estradas e o tempo mais expandido para troca de informações.

Veneza torna-se um destino turístico por razões diversas do que Roma. Desde as cruzadas, torna-se o elo por excelência entre o oriente e o oriente. Desde a queda de Roma e a mudança da capital para Constantinopla, Veneza se transforma no entreposto comercial mais importante e ponto de referência para as cruzadas. Logo, a presença oriental é mais marcante do que a herança clássica nesta cidade. Seu primeiro guia turístico foi escrito pelo grande arquiteto Sansovino, no final do século $\mathrm{XVI}$.

Ao discorrer sobre viajantes impossível não mencionar os portugueses que, em setenta anos, percorrem por mares nunca dantes navegados. As datas são impressionantes: Em 1464 - cabo Bojador, 1471 a linha do equador, 1488 -Cabo da boa esperança, 1498 - India, 1500 - Brasil, 1513 - China, 1522 - Austrália, 1542 Califórnia, Japão-1543, Nova Zelândia - 1550. Navegar é preciso viver não é preciso como nos diz Fernando Pessoa.Certa vez estiva em Hoi an no Vietnã e parecia que não estava muito distante de Parati...

Um tema a ser melhor estudado é a predominância da cultura literária portuguesa sobre as artes plásticas pelo menos até o século XIX. Nosso país nasce de uma carta e não de um desenho, embora no tratado de Tordesilhas a américa espanhola e portuguesa seja dividida por um traço. As imagens que temos do Brasil foram feitas até então por estrangeiros, seja na corte de Mauricio de Nassau, seja na corte de dom João $\mathrm{VI}^{9}$ onde a pesquisa dos viajantes muitas vezes era controlada como uma questão de estado ${ }^{10}$.

trocar e comparar experiências de viagem e de contemplação de paisagens era comum na sociedade elegante. WILLIAN. R. O Campo e a Cidade. Cia das Letras..

\footnotetext{
9 A colonização do Brasil foi historicamente retratada por Jean Baptiste Debret (1768-1848) que registra a corte de Napoleão Bonaparte e oficialmente a Coroa Portuguesa no Brasil. No livro Viagem Pitoresca e a História do Brasil (1834-1839), documenta o cotidiano da sociedade brasileira no início do século XIX, os aspectos rudes e pobres da realidade. No primeiro volume aborda a cultura indígena, no segundo, a relação entre brancos e negros e no terceiro, as tradições populares e a corte. "Sob a influência dos padrões neoclássicos europeus, essas instituições orientaram as artes visuais ao longo do século, não sem antes opor conflitos graves entre os artistas novos e liberais e os lusitanos, bem mais conservadores. Nas gravuras e aquarelas de Debret encontramse algumas das mais preciosas imagens para se compreender a vida colonial, o cotidiano do escravismo, que geraram uma forma plástica concernente à condição colonial brasileira. Segundo a tese do crítico de arte e historiador Rodrigo Naves, o francês Debret foi, paradoxalmente, o primeiro pintor "brasileiro", no sentido de haver criado uma forma plástica capaz de dar conta da especificidade e da diferença da cultura local diante dos padrões europeus modernos." ALAMBERT. F. http://latinoamericana.wiki.br/verbetes/a/artes-plasticas acesso em 24 de Março de 2020 e Ver ainda PEDROSA, M, "Da Missão Francesa - Seus Obstáculos Políticos". In: Arantes, Otília Beatriz Fiori. (org.). Acadêmicos e Modernos III. São Paulo: EDUSP, 1998, pp. 41-114. 3.

10 GOMES.L. 1808 e book p. 432 "A intenção portuguesa de conservar o Brasil fechado para o mundo é ilustrada pela ordem de prisão emitida em julho de 1800 contra o barão, naturalista e geógrafo alemão Alexander Von Humboldt, que na época percorria a região amazônica em busca de novas espécies da fauna e da flora. Ignorando o valor científico da expedição, o governo português considerou sua presença prejudicial aos interesses da Coroa pelas ideias perigosas que ele poderia disseminar na Colônia."
} 
"Até 1808, a temática religiosa dominou por completo a produção artística no país, entre o período que engloba o século 16 até a primeira década do século 19 com exceção das obras de Franz Post e Albert Eckhout, que retrataram a paisagem, a flora, a fauna, a dança dos índios Tapuias, os tipos humanos e os empreendimentos açucareiros em Pernambuco. ${ }^{11 "}$

$\star \star \star$

Toda cidade resulta composta do entrelaçamento de temporalidades diversas afirma Argan12. Voltando a avenida Paulista, basta olharmos atentamente para notarmos como ela é constituída por uma arquitetura eclética que vai do início do século XX até edificações que estão sendo feitas no presente momento com a tecnologia mais avançada.

Podemos abordar a cidade das mais várias maneiras, da sua estrutura viária, suas histórias do passado, suas transformações econômicas e assim por diante. Visto que estamos numa área focada mais em arte e arquitetura é vital que tenhamos uma abordagem fenomenológica que de maneira sucinta abordamos no início deste artigo. Para isso é preciso acreditar que as imagens efetivamente nos dizem algo e que podemos as ordenar e as transformar produzindo novos significados. $O$ mundo que se oferece à câmara é diferente do que se oferece a visão. Podemos também afirmar que se estivermos com um caderno de desenho ou aquarela nossa intenção de figurar o mundo também será distinta.

$\star \star \star$

Às vezes, quando me assalta um curioso desejo por tais aventuras, invejo o viajante que vê tais maravilhas numa relação cotidiana e vive com outras maravilhas. Mas ele também se torna um outro homem. Ninguém passeia impunemente sob palmeiras, e certamente as visões de mundo modificamse, num país onde elefantes e tigres sentem-se em casa.

J. W. von Goethe, excerto do diário de Ottilie, As afinidades eletivas, 1809.

\footnotetext{
${ }^{11}$ Até 1808, a temática religiosa dominou por completo a produção artística no país, entre o período que engloba o século 16 até a primeira década do século 19 - com exceção das obras de Franz Post e Albert Eckhout, que retrataram a paisagem, a flora, a fauna, a dança dos índios Tapuias, os tipos humanos e os empreendimentos açucareiros em Pernambuco.

A partir de 1808, com a chegada da família real ao Brasil, os temas profanos passaram a ser adotados pelos artistas brasileiros, e algumas décadas depois já prevaleciam nas artes plásticas em nosso país. "No século XIX, com a presença da missão francesa de arquitetos e artistas no brasil, também ocorreu a representação do país e de sua sociedade por artistas como Debret e Taunay, entre outros. No correr do segundo império os temas das pinturas brasileiras serão sobretudo patrióticos.

Com o advento da semana de Arte moderna em 1922, inverteu-se a situação com o predomínio do profano e nossos modernistas e depois nossos contemporâneos se fizeram conhecidos do grande público por obras que não expressavam o sentimento religioso", comenta o diretor executivo do MASP, José Carlos Marçal de Barros.
}

12 IDEM, p.88 
Certo dia, pesquisando na internet sobre as viagens de Goethe me deparo com um artigo extremamente instigante de Arley Andriolo, professor do Departamento de Psicologia Social e do Trabalho do Instituto de Psicologia da USP. O título do seu artigo é Metamorfoses do olhar- viagem de Goethe à Itália. ${ }^{13} \bigcirc$ mais curioso é o fato de que Arley na verdade trabalha no prédio vizinho ao Departamento de Artes Plásticas da USP e só nos encontramos uma vez quando o procurei devido ao artigo.

Segundo o autor "pesquisas em ciências humanas direcionadas à experiência da viagem, seja compreendida pelo mundo dos viajantes, seja de modo restrito ao turismo, têm indicado três às principais relações constituintes: com o espaço, com o outro, com o eu (ou em relação a si)". Este texto retoma essas relações na compreensão das dimensões geral e particular do deslocamento espacial, frente ao fenômeno da percepção, procurando inscrever nessas três relações um quarto elemento: o tempo.

De certa forma abordamos e estas questões no início deste artigo, ao analisar como a viagem segundo a fenomenologia produz um estranhamento na percepção devido ao deslocamento no tempo e no espaço. As transformações técnicas que ocorreram ao longo do século XVIII por sua vez conferem primazia ao órgão visual ${ }^{14}$.

Goethe é importante neste relato na medida em que sua viagem à Itália desperta no poeta não só uma inspiração pictórica, mas a vontade de pesquisar fenômenos a partir do seu olhar. Cerca de 20 anos mais tarde publica em 1810 a primeira parte de sua Doutrina das cores onde procura discorrer sobre a cor numa perspectiva fisiológica inaugural. Para um viajante vindo da Europa do norte o colorido da pintura e da paisagem italiana fazem ele renascer de novo ${ }^{15}$. $O$ poeta chega a questionar sua vocação e realiza aquarelas ${ }^{16}$ durante sua viagem. Guiava-se assim mais por suas impressões do que por guia turísticos, mesmo que tenha feito uma vasta pesquisa histórica e iconográfica. Sua inclinação a viajar é motivado tanto pela influência

\footnotetext{
13 "Este artigo objetiva apresentar a atitude de Goethe em sua Viagem à Itália em relação a uma nova forma de perceber no final do século XVIII, considerando a transformação histórica que elevou o olho em meio aos outros órgãos da percepção. Por outro lado, a situação histórica de Goethe era orientada por um processo particular interior no sentido de desenvolver um método de observação crítico. Ao final, a partir das palavras desse poeta alemão, indica-se a importância da viagem como um movimento através do espaço, do tempo, do outro e de si. Quando ele observava a paisagem, seu campo de percepção mudava e produzia uma experiência estética que Ihe apresentava o fenômeno arquetípico (Urphänomen)?' ANDRIOLO, ARLEY. Metamorfoses do olhar- viagem de Goethe à Itália.

${ }^{14}$ Goethe apresenta a opacidade do observador como condição à aparência do fenômeno. Na abordagem de Crary, a cultura visual que emergia na Europa no século XIX considerava tanto as ciências relacionadas à ótica, o observador e seu corpo, quanto novos aparatos, tais como estereoscópio, caleidoscópio, diorama, aos quais se poderá acrescentar as práticas de visitas guiadas e o sightseeing na origem do mundo do turismo.

IDEM, p, 123

CRARY, Jonathan. Tecniques of the observer. October, n. 45, summer, 1988, pp. 1-35. Na versão em português: Jonathan Crary -Técnicas Do Observador: Visão e Modernidade. Tradução: Nuno Quintas Editor: Orfeu Negro Edição ou reimpressão: janeiro de 2017.

15 Em 10 de novembro estava em Roma: "a capital do mundo".16 Permanece até 22 de fevereiro de 1787. A riqueza da experiência de Goethe nesta cidade foi sintetizada pelo próprio escritor ao considerar: "o dia em que cheguei a Roma como a data do meu segundo nascimento, de um verdadeiro renascimento". GOETHE, Johann Wolfgang von. Viagem à Itália. São Paulo: companhia das letras, 1999, p. 148. também WERLE, Marco Aurélio. Introdução in: GOETHE, Johann Wolfgang von. Escritos sobre arte. São Paulo: Imprensa Oficial / Humanitas, 2005.

${ }^{16}$ Foi na Itália que os artistas desenvolveram a técnica da mecânica da pintura com aquarela - o emprego de certas tintas com o intuito de produzir determinados tons - sem se conhecer o segredo, passaríamos a vida inteira misturando as cores até chegar a eles" GOETHE Viagem à Itália, p.275.
} 
paterna como pelo hábito de colecionar" ${ }^{17}$. Como Petrarca "se punha a caminhar munido de folhas de desenho entre vales e colinas... 'A busca agora é pelo ar livre; se, até agora, deuses e heróis foram o alvo exclusivo de atenção, eis que a paisagem reaparece, clamando por seus direitos, prendendo o olhar nas cercanias às quais o dia magnífico empresta vida." ${ }^{18}$. Anos mais tarde Goethe escreve os Anos de aprendizado de Wilhelm Meister e inaugura um novo tipo de romance o Bildungsroman (romance de formação) onde o Wilhelm sai da casa dos pais e se junta a uma trupe de teatro. Sua formação se efetiva na vida prática, no mundo, em viagem permanente. Neste livro se encontra o famoso poema sobre uma viagem imaginária à Itália. Observem que temos uma experiência sinestésica ao participar desta aventura:

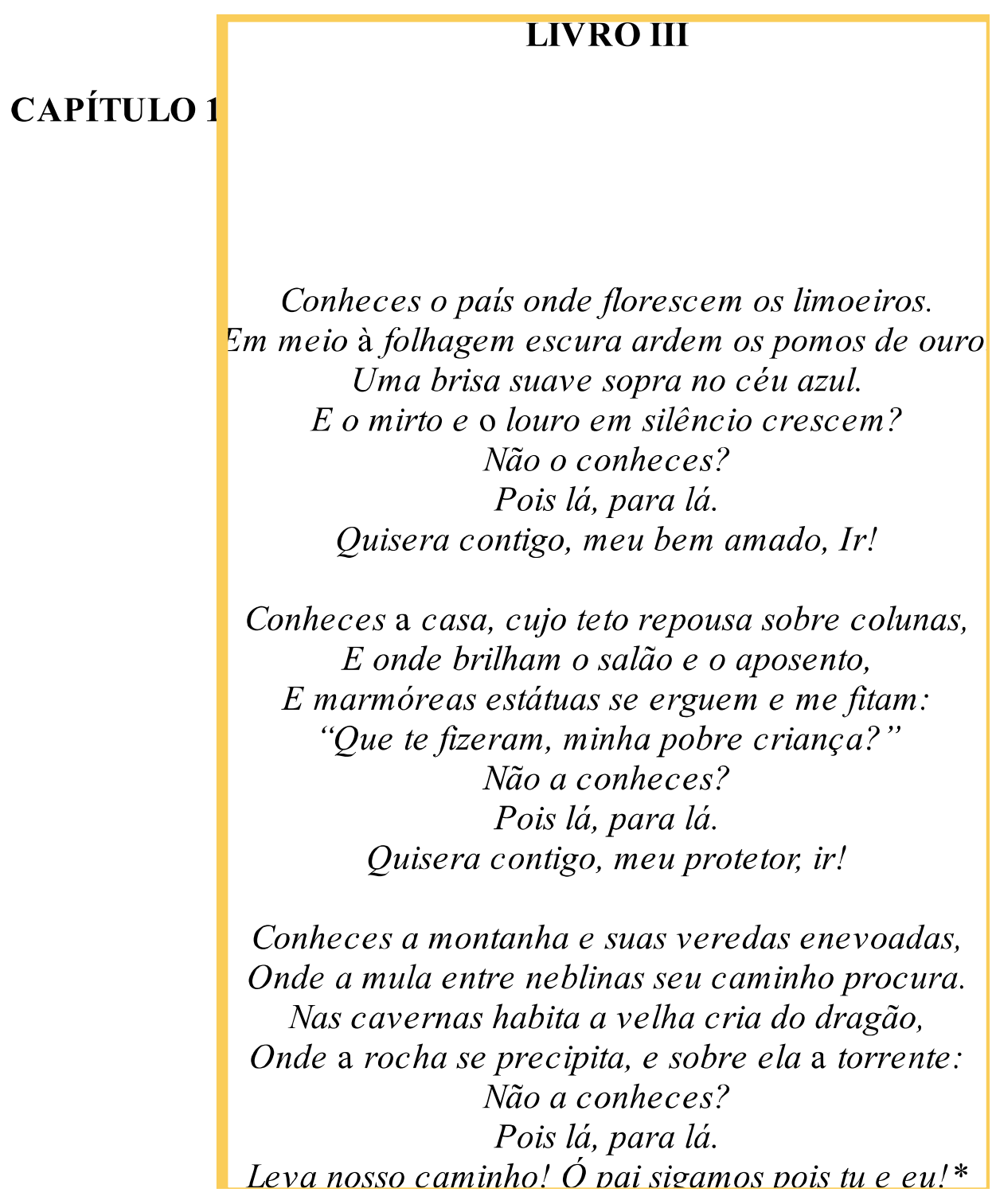

No final do século XVII século e início do século XVIII século, desenvolve na Itália um tipo particular paisagem, essencialmente urbana, contemporânea, com grande precisão topográfica, a "Veduta" (ver, em italiano). Essas visões remetem à percepção óptica, são frequentemente feitas com instrumentos, em particular a "câmara obscura". Os vedutistas trabalhavam principalmente para ricos estrangeiros, especialmente 
ingleses, que estavam em uma espécie de viagem de formação e gostavam de ter como lembrança vistas específicas de Roma ou Veneza, daí a necessidade de precisão topográfica e pequeno formato.

O calvinismo dominante e o regime republicano não eram muito favoráveis ao florescimento da pintura religiosa e da história nos países do norte da Itália. Logo, os pintores alemães, flamengos e holandeses são muito ligados a pintura de paisagem. Albrecht Dürer, que viajou duas vezes para a Itália para através dos Alpes, encheu cadernos com paisagens de montanhas. Já os holandeses estavam orgulhosos de um país que eles criaram em parte empurrando o mar para trás e de onde se libertaram do domínio espanhol.

Com o Romantismo a paisagem dos desertos, alpes ou do mar revolto, antes desvalorizados como algo perigoso, inóspito e até mesmo feio passa a ser valorizado como algo sublime. A paisagem se torna um assunto em si, que provoca sentimentos no sujeito. Até então todas essas paisagens foram reconstruídas no atelier. Um passo decisivo será dado com o desenvolvimento ferroviário e a invenção do tubo de tinta, de modo que os pintores possam trabalhar ao ar livre. Camille Corot (1796 1875) foi um dos primeiros a fazer isso, embora também tenha trabalhado muito no atelier. Suas pinturas sobre o campo romano ensolarado, suas paisagens de Ilha de França banhadas por uma luz suave o fazem, segundo Delacroix, "o pai da paisagem moderna".

Em 1863, a Escola de Belas Artes aboliu o Prêmio de Roma para a Paisagem histórica, que se tornara irrelevante. No mesmo ano, Edouard Manet foi recusado no Salon por ter introduzido mulheres nuas de origem duvidosa na paisagem de seu "almoço na relva" ( déjeuner sur l'herbe). Neste caso a paisagem mais parece um cenário artificial para uma cena campestre. Manet causou grande estranhamento ao fazer uma obra feita de colagens de gêneros e referências pictóricas.

Ao final do século XIX, a paisagem atingirá seu ápice com o impressionismo (1872: Impression, Soleil levant de Claude Monet.) Como nas paisagens de Turner (1775 - 1851), o tema é dissolvido em favor da atmosfera, da vibração da luz, dos reflexos da água; os contornos desaparecem, a pincelada se torna mais evidente ${ }^{19}$. Como diz o título, mais do que o sol nascendo, o que importa é a impressão fisiológica que causa no pintor o tema da própria pintura. Mais do que discorrer sobre o tema da paisagem de forma sucinta o importante é mostrar como estes artistas efetivamente passam sistematicamente a viajar em busca de temas para desenvolver seu trabalho. Delacroix vai para Marrocos em busca da luz do mediterrâneo e do orientalismo em voga, Turner e Monet buscam Veneza a cidade que reverbera a cor em seus canais. Matisse e Klee descobrem a intensidade da cor no norte da africa ao ponto de Klee afirmar que "eu e a cor somos uma coisa só, sou um pintor".

Se na primeira aula fizemos uma distinção entre ver e olhar, abordo aqui casos em que os pintores viajantes olham para natureza na busca da construção de sua poética. Algo muito distante do que artistas de países periféricos como no caso

\footnotetext{
${ }^{19}$ https://www.augustins.org/documents/10180/15597506/papp01s.pd acesso em 24 de Março de 2020.
} 
brasileiro, que foram para Paris para pintar conforme os padrões estipulados pela academia francesa. Não é este tipo de viagem nem este tipo de formação que tenho em mente neste artigo.

O leitor pode estranhar que até agora mais tenha se falado sobre paisagem do que sobre a cidade. Creio que a paisagem urbana surge como um desdobramento da pintura da paisagem justamente no momento em que grandes metrópoles urbanas crescem de uma maneira impressionante no final do século XIX. Com a revolução industrial o homem passa a habitar muito mais os centros urbanos do que o campo.

Um dos propósitos deste artigo é efetivamente incentivar os alunos a viajarem, não para fazer turismo, mas para apreender a olhar o mundo numa nova ótica, mesmo que seja na sua própria cidade.

Em um poema sobre a Odisséia, Kafávis nos diz:

Se partires um dia rumo a Ítaca, faz votos que o caminho seja longo, repleto de aventuras, repleto de saber.

\section{Referências:}

CARDOSO, S. O Olhar viajante (do etnólogo) in: NOVAES et al- O OLHAR- São Paulo, Cia das Letras, 1988, p.347-360.

ARGAN, Giulio Carlo. História da Arte como história da cidade. Martins Fontes, 1992.

HOMERO, traducão e introdução, Christian Werner, Cosac Naify, São Paulo, 2014.

FIGUEREDO, V. (Org) Filosofia: temas e percursos. Editora Berlendis, São Paulo, 2018. 